\title{
Stability of peptides during iontophoretic transdermal delivery
}

\author{
Yi-You Huang*, Shian-Min Wu \\ Center for Biomedical Engineering, College of Medicine, National Taiwan University, No. 1, Sect. 1, Jen-ai Road, Taipei, Taiwan. \\ $R O C$
}

Received 26 May 1995; accepted 12 July 1995

\begin{abstract}
Degradation of thyrotropin releasing hormone (TRH) and insulin was investigated during iontophoretic transdermal delivery in vitro in varied buffer solutions and under various experimental conditions. A large current density enhanced deterioration of TRH during transdermal iontophoresis. Skin or external electrical potential increased the rate of deterioration, as did elevated temperatures. Peptide transformations took place and were significantly influenced by the physiological and pathological status of the skin and the electrochemical conditions during iontophoresis. Skin metabolism and electrical deterioration during iontophoretic transdermal transport was significant, especially at elevated temperature. Decreased temperature or added agents decreased the rate of degradation.
\end{abstract}

Keywords: Thyrotropin releasing hormone; Insulin; Stability; Iontophoresis; Transdermal

\section{Introduction}

Transdermal delivery provides a means of administering drugs noninvasively to the body (Cullander and Guy, 1992). Iontophoretic transdermal delivery allows a large rate of controlled delivery and drugs can be delivered at varied times (Banga and Chien, 1988; Jaw et al., 1995). Past work on iontophoretic drug delivery was aimed mainly at topical treatment. Recently, transdermal iontophoresis is investigated for sys-

* Corresponding author. temic administration and for delivery of peptide and protein drugs (Srinivasan et al., 1989; Green et al., 1992).

Although, skin has much less proteolytic enzyme than other mucosa (Lee, 1988), degradation of drugs during transdermal iontophoresis remains problematic (Martin et al., 1987). The chemical and physicochemical stability of drugs is important in the application of iontophoresis as a delivery system. In this work, the stability of TRH and insulin during iontophoresis was investigated. Normal human insulin and ${ }^{125}$ I-labelled insulin were used simultaneously to test the delivery and rate of degradation of insulin through skin during iontophoresis in vitro. 


\section{Materials and methods}

All chemicals used in experiments were of reagent grade (Sigma Chemical Company, St. Louis, MO, USA, or Wako Chemicals, Japan). Human insulin powder (Eli-Lilly, Indianapolis, MO, USA), ${ }^{125}$ I-labelled porcine insulin (DuPont, Boston, USA) and insulin radioimmunoassay kits (Diagnostic Products Corporation, CA, USA) were obtained from the indicated suppliers.

Side-by-side diffusion cells (model VSC-1, Crown Glass, Somerville, NJ) were used in all degradation and permeation experiments. Platinum wires served as electrodes. The electrodes were connected to a universal power source (Hewlett Packard HP 3245A, Palo Alto, CA). The donor and receptor cells were filled with phosphate solution at $\mathrm{pH} 7.4$ or citrate solution at $\mathrm{pH}$ 3.6. Rabbit inner pinna skin, freshly excised from female New Zealand white rabbits $(3-5 \mathrm{~kg}$, obtained from the animal center in the College of Medicine) were used for tests of permeation. The outermost layers of skin (epidermis), taken from the animals immediately after their being killed, were used.

Concentration of TRH and insulin were analyzed with capillary electrophoresis (Beckman, P/ ACE System 2100) with an on-line UV detector.

\section{Results and discussion}

\subsection{Degradation of peptides under iontophoresis}

Fig. 1 shows the degradation of TRH at various current density $\left(0,0.128,0.32,0.64 \mathrm{~mA} / \mathrm{cm}^{2}\right)$ during iontophoresis. At a small current density $\left(<0.32 \mathrm{~mA} / \mathrm{cm}^{2}\right)$, TRH was stable at $37^{\circ} \mathrm{C}$ in citrate buffer at $\mathrm{pH} 4.0$ during the period of iontophoresis. When the current density was increased $>0.32 \mathrm{~mA} / \mathrm{cm}^{2}$, degradation increased. TRH deteriorated quickly at a current density of $0.64 \mathrm{~mA} / \mathrm{cm}^{2}$ : more than $75 \%$ of drug degraded after iontophoresis for $10 \mathrm{~h}$.

Preliminary tests were performed to characterize the pattern of elution during capillary electrophoresis with freshly prepared standard solutions of insulin. More than three major degra- dation products formed during experiments. The area of insulin signal decreased as it degraded and the corresponding areas of signals of degradation products increased. Capillary-electrophoretic analysis revealed that signals of degradation products became broader if the products became cleaved into smaller segments (Fig. 2).

According to its chemical structure, insulin might degrade enzymatically, beginning at either disulfide bonds or peptide bonds. Insulin and peptides are susceptible to hydrolysis and chemical transformation. Insulin is more stable in a neutral environment, such as phosphate buffer at $\mathrm{pH} 7.4$, over a 24 -h period if skin is not added or current is not applied. Addition of animal epidermal skin to the solution caused increased degradation of insulin. Passage of current caused insulin to degrade even more rapidly (Fig. 3).

During the first $8 \mathrm{~h}$, insulin degraded by only about $9 \%$ in control buffer. On addition of skin, degradation increased to $40 \%$. On passage of current, insulin degraded by $70 \%$ during the first $8 \mathrm{~h}$. Insulin initially deteriorated rapidly but then more slowly during iontophoresis. All insulin was totally degraded within $24 \mathrm{~h}$ regardless of conditions tested. The half-lives of insulin in these stability tests were 16,11 and $6 \mathrm{~h}$, respectively. In control solution, degradation followed the deactivation behavior. When in contact with skin, degradation of insulin followed linear kinetics. Current caused degradation in a two-step manner.

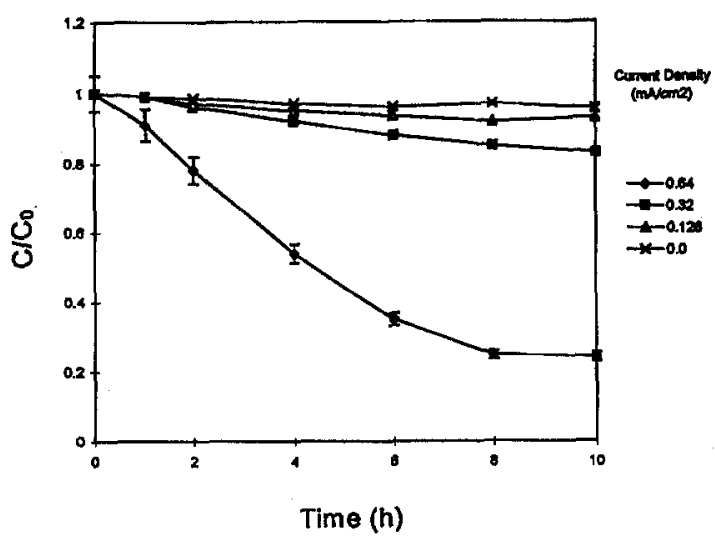

Fig. 1. Degradation of TRH at $37^{\circ} \mathrm{C}$ in a citrate buffer at $\mathrm{pH} 4.0$ during iontophoresis. $C_{0}$, initial concentration of TRH. 

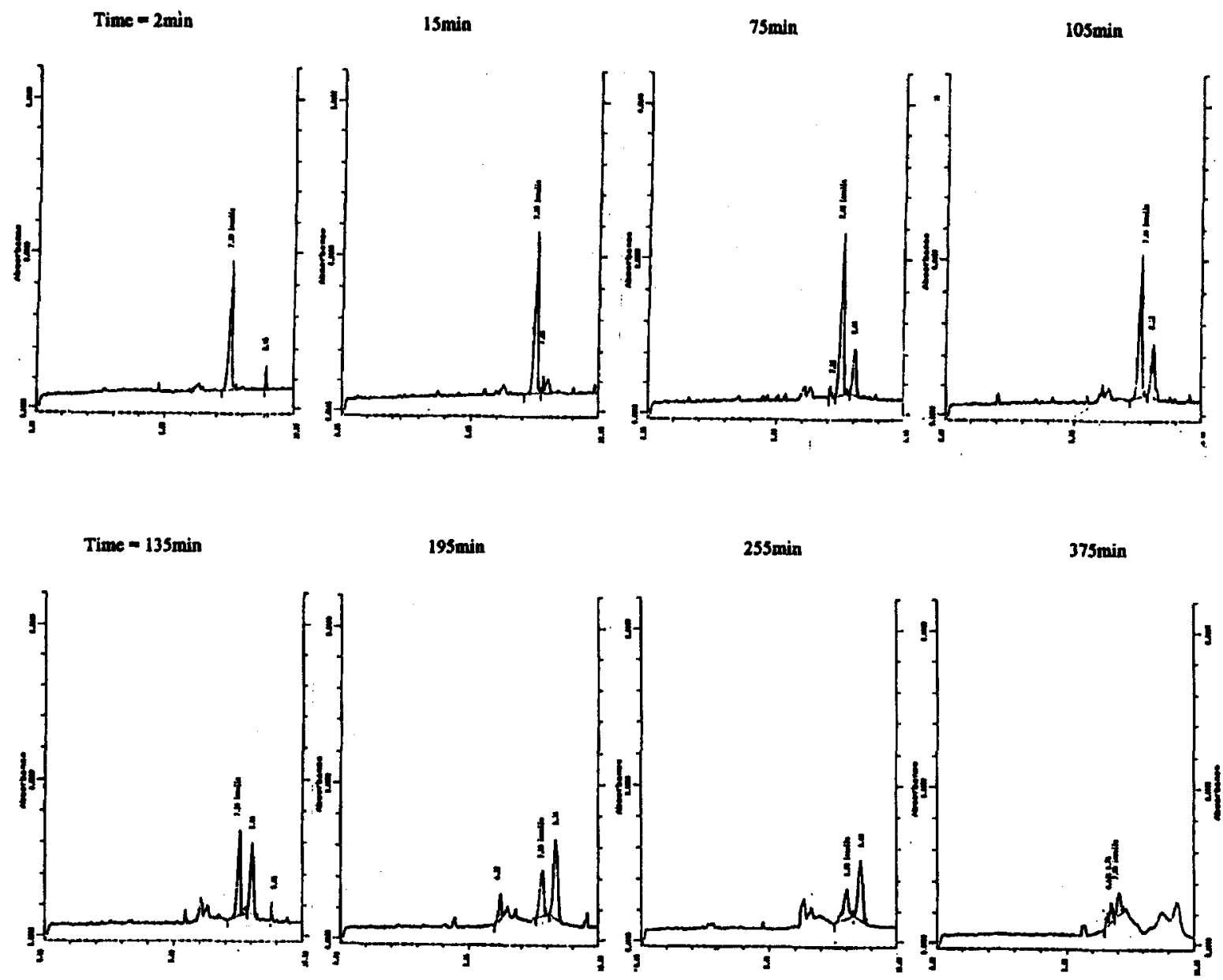

Fig. 2. Degraded insulin peak at a successive times.

\subsection{Effect of temperature}

Insulin degradation was sensitive to temperature. Insulin is unstable at high temperatures. Deterioration was rapid over a 24-h period (Fig. 4). When no preservatives or antibiotics were added, insulin integrity was retained at $4^{\circ} \mathrm{C}$ in solution during the experimental period. At $25^{\circ} \mathrm{C}$, half the insulin was lost within 2 days. When the solution temperature was raised to $37^{\circ} \mathrm{C}$, degradation proceeded more quickly. According to regression analysis the rate of degradation was proportional to temperature. Addition of skin to insulin solutions at $37^{\circ} \mathrm{C}$ caused rapid loss of insulin.

\subsection{Permeation test through a synthetic membrane at different temperatures}

Synthetic polyvinyl alcohol (PVA) membrane was fabricated by the casting method (7\% PVA +2 g PEG $4000+43 \mathrm{~g} \mathrm{H}_{2} \mathrm{O}$ ). The membrane was then mounted between diffusion cells. In the donor side, $206.5 \mu \mathrm{g} / \mathrm{ml}$ of insulin was loaded. Insulin penetrated through the membrane to the receptor side by passive permeation. At $4^{\circ} \mathrm{C}$, the cumulative concentration of insulin increased with time, as shown in Fig. 5. While the temperature was raised to $37^{\circ} \mathrm{C}$, only in the first hour was the concentration of insulin high enough to be assayed by capillary electrophoresis. After $4 \mathrm{~h}$, none 


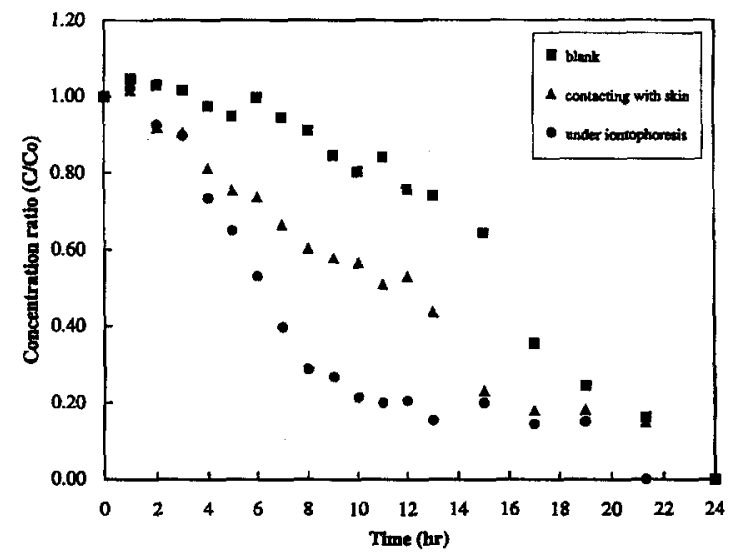

Fig. 3. Decay of insulin in phosphate buffer at $\mathrm{pH} 7.4$ during iontophoresis or in the presence of skin.

of insulin in the donor side could be detected. This indicates that high temperature caused deterioration of almost all of the insulin within a short period of time. Decreased temperature could reduce the rate of degradation.

\subsection{Permeation test of insulin through skin under iontophoresis}

A fixed ratio of hot drug ( ${ }^{125}$ I-labelled insulin) to cold drug (unlabelled insulin), $1 \mathrm{cpm}$ to 40 $\mu \mathrm{IU}$, was added to a donor solution. Iontophoresis was run at $37^{\circ} \mathrm{C}$, with a current density of 0.64 $\mathrm{mA} / \mathrm{cm}^{2}$, pulsed current, frequency $2000 \mathrm{~Hz}$, and

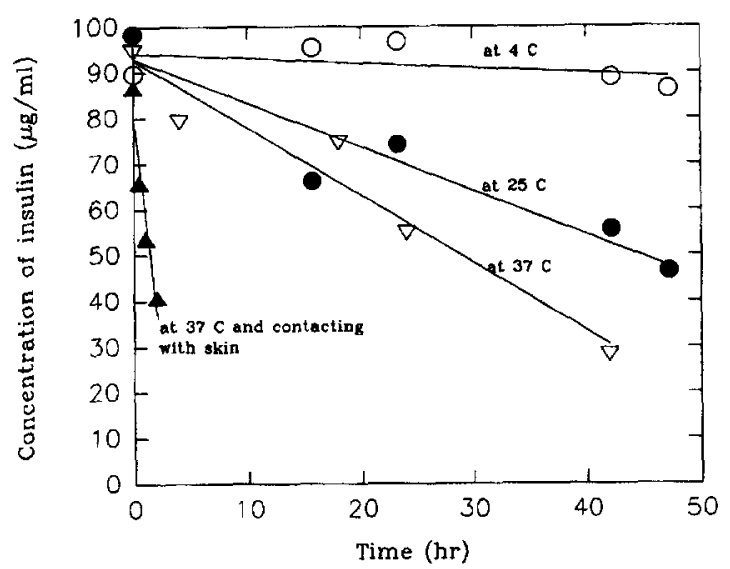

Fig. 4. Influence of temperature on degradation of insulin.

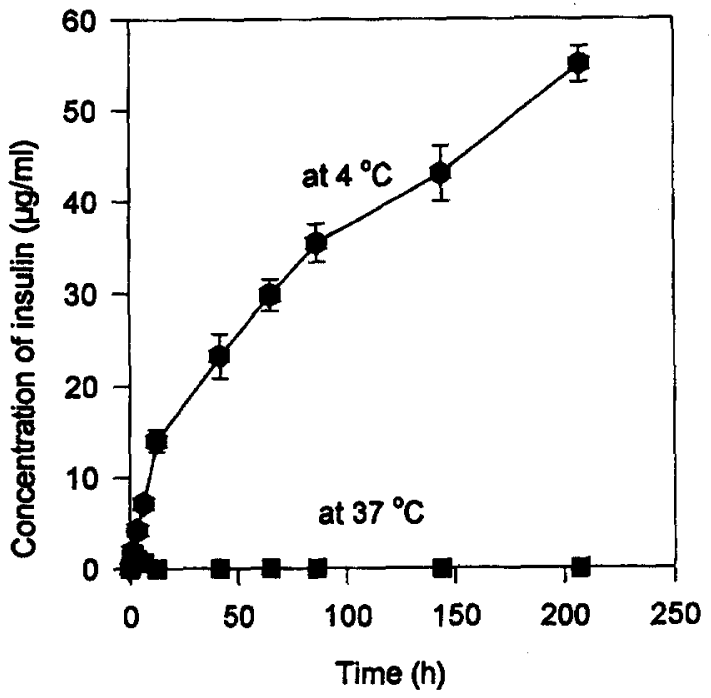

Fig. 5. Accumulative amounts of insulin during passive permeation at different temperatures.

on/off ratio 1:1. During iontophoresis, insulin penetrated through the skin to the receptor side, but the ratio of labelled to unlabelled drug altered. This means that insulin transmuted during iontophoretic transdermal passage. The ratio in the receptor side decreased greatly. At the end of the experiments, almost no intact insulin was found in the receptor side, as shown in Fig. 6.

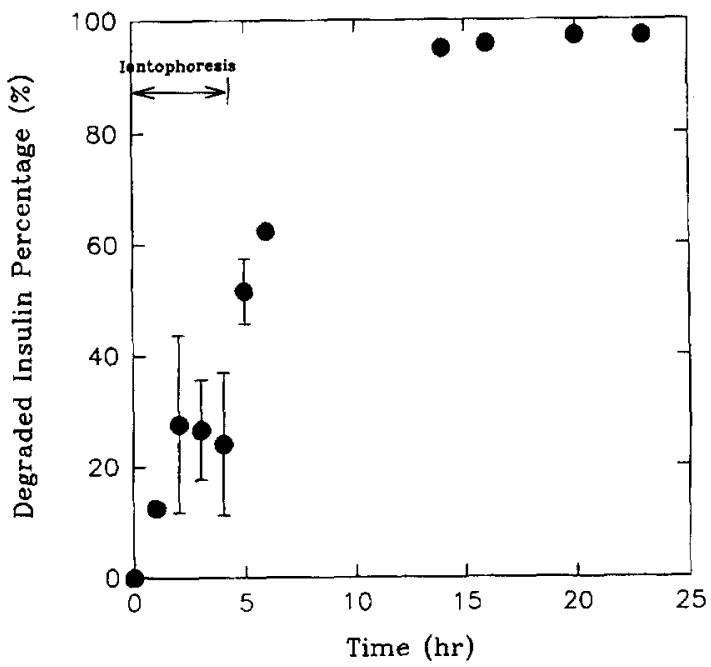

Fig. 6. Decay of insulin during permeation experiments under iontophoresis. 
This result shows that almost all insulin was degraded as it passed through skin during iontophoresis. The ratio of degradation increased with time. Cutaneous metabolism and electrical deterioration during iontophoretic percutaneous transport was significant. If the receptor solution had been phosphate buffer, insulin may have been more stable.

\section{Conclusions}

Degradation of TRH and insulin was tested during iontophoretic transdermal delivery in vitro in varied buffer solutions and under various experimental conditions. A large current density enhanced deterioration of TRH during transdermal iontophoresis. In degradation tests, insulin deteriorated rapidly during iontophoresis if without addition of preservatives; degradation was more rapid in an acidic environment than at neutral $\mathrm{pH}$. Skin or external electrical potential increased the rate of deterioration, as did elevated temperatures. In permeation experiments, large variation of quantities of drug accumulated in the receptor solution were found between radioimmunoassay and isotopically labelled drug $\left({ }^{125} \mathrm{I}\right.$-labelled porcine insulin) methods. When porcine insulin labelled with ${ }^{125} \mathrm{I}$ was used at the donor side, apparent permeation (radioactivity) increased with current, whereas biological activity did not. The ratio of degradation increased with time. Clearly, drug transformations took place and were significantly influenced by the physiological and pathological status of the skin and the electrochemical conditions during iontophoresis. Cutaneous metabolism and electrical deterioration during iontophoretic transdermal transport was significant, especially at elevated temperature. Decreased temperature or added agents decreased the rate of degradation.

\section{Acknowledgements}

We thank the Ministry of Health of the Republic of China (grant DOH84-HR-310) for financial support.

\section{References}

Banga, A.K. and Chien, Y.W., Iontophoretic delivery of drugs: fundamentals, developments and biomedical applications. J. Controlled Release, 7 (1988) 1-24.

Cullander, C. and Guy, R.H., Routes of delivery: case studies (6). Transdermal delivery of peptides and proteins. $A d v$. Drug Del. Rev., 8 (1992) 291-329.

Green, P., Shroot, B., Bernerd, F., Pilgrim, W.R. and Guy, R.H., In vitro and In vivo iontophoresis of a tripeptide across nude rat skin. J. Controlled Release, 20 (1992) 209-218.

Jaw, F.S., Wang, C.Y. and Huang, Y.Y., Portable current stimulator for transdermal iontophoretic drug delivery. Med. Eng. Phys., 17 (1995) 385-386.

Lee, V.H., Enzymatic barriers to peptide and protein absorption. Crit. Rev. Ther. Drug Carrier Syst., 5, (1988) 69-97.

Martin, R.J., Denyer, S.P. and Hadgraft, J., Skin metabolism of topically applied compounds. Int. J. Pharm., 39 (1987) $23-32$.

Srinivasan, V., Higuchi, W.I., Sim, S.M., Ghanem A.H. and Behl, C.R., Transdermal iontophoretic drug delivery: Mechanistic analysis and application to polypeptide delivery. J. Pharm. Sci., 78 (1989) 370-375. 